\title{
TOTEK gözüyle ortopedi ve travmatoloji eğitimi
}

\section{Orthopaedics and traumatology education from the point of view of TOTEC}

\author{
Alpaslan Şenköylü \\ Gazi Üniversitesi Tıp Fakültesi, Ortopedi ve Travmatoloji Anabilim Dalı, Ankara
}

Türk Ortopedi ve Travmatoloji Eğitim Konseyi (TOTEK), uzmanlık eğitimini yükseltmek ve kalitesini standardize etmek amacıyla kurulmuş bir organdır. Eğitimin standardizasyonunda resmi sorumlu Sağlık Bakanlığı ve Türk Tabipler Birliği olmakla birlikte, TOTEK'in sivil toplum örgütü olarak fiili sorumluluğu vardır.

Eğitimin temel taşları program geliştirme ve ölçmedeğerlendirmedir. TOTEK her iki konuda da görevlendirilmiş komisyonlarıyla eğitim programı geliştirerek, eğitim etkinlikleri düzenlemektedir. Geliştirilen programlar, çekirdek eğitim programları ve asistan karneleridir. Etkinlikler ise Çekirdek Eğitim Programı Kursu, Temel Bilimler Araştırma Okulu ve Ortopedi Bilgi Ağı'dır.

TOTEK'in ölçme ve değerlendirme etkinlikleri, her yıl düzenli olarak gerçekleştirilen sertifika sınavı ve uzmanlık eğitimi gelişim sınavıdır. TOTEK aynı zamanda eğitim kurultayları da düzenleyerek eğitim stratejilerini güncelleştirmektedir.

Çok sayıda eğitim kurumu olan ve değişken sağlık-eğitim politikaları uygulanan ülkemizde eğitimde standardizasyon vazgeçilmezdir. Bunun için, eğitim kurumlarının ve üyelerimizin desteklerini sürdürmesi gereklidir.

Anahtar sözcükler: uzmanlık eğitimi; ortopedi ve travmatoloji; program gelişimi; ölçme ve değerlendirme
Turkish Orthopaedics and Traumatology Education Council (TOTEC) was established in order to foster increasing and standardizing the quality of specialty training in Turkey. In fact, the intitutions formally responsible for this task are the Ministry of Health and Turkish Physicians Association. However, TOTEC also has de facto responsibility as a non-governmental organization.

Essential elements of education are program development and measurement-assessment. There are assigned committees within TOTEC, developing and organizing educational programs and activities on these topics. These are mainly: Core Curriculum Trainees' Portfolio, Basic Science Research School and Orthopaedics Knowledge Network.

Measurement and assessment activities of TOTEC are board exam and interim exam for trainees arranged every year regularly. Moreover, TOTEC updates the educational strategies by organizing general assemblies.

In our country, where many institutions in different levels and with unstable health-education politics prevail, standardization is crucial. In order to achieve this goal, it is necessary that the members of our society and educational institutions both maintain their valuable support.

Key words: specialty training; orthopaedics and traumatology; program development; measurement and assessment
Eğitimli bir cerrahın özgüvenli ve yeterli olduğuna şiddetle inanırım. Belki de bunun sebebi, insanın bilmediği şeyler konusunda bildiklerine göre kendinden daha emin olmasındandır. Hepinizi eğitim olgusunu incelemeye, sahiplenmeye, kendinizi zorlamaya ve mükâfatların zevkini çıkartmaya davet ediyorum.

Randal R. Betz ürk Ortopedi ve Travmatoloji Eğitim Konseyi (TOTEK), 2001 yılında Türkiye'de ortopedi ve travmatoloji uzmanlık eğitiminin kalitesinin yükseltilmesi ve eğitim birimlerinin standardizasyonunun sağlanması amacıyla kurulan ve doğrudan Türk Ortopedi ve Travmatoloji Birliği Derneği (TOTBiD) Yönetim Kurulu'na bağlı olarak çalışan bir organdır. [1] TOTEK yaptığı eğitim ve ölçme-değerlendirme etkinlikleriyle hem uzmanlık öğrencilerinin hem de uzmanların mezuniyet sonrası eğitimlerini standardize

- Illetişim adresi: Prof. Dr. Alpaslan Şenköylü, Gazi Üniversitesi Tıp Fakültesi, Ortopedi ve Travmatoloji Anabilim Dalı, Beşevler, Ankara Tel: 0312 - 2025502 e-posta: senkoylu@gazi.edu.tr

- Geliș tarihi: 24 Ekim 2014 Kabul tarihi: 24 Ekim 2014 
edilmesini hedefler. Bu amaçla, TOTEK yönetim kurulu üyelerinden Eğitim Programı Geliştirme ve ÖlçmeDeğerlendirme Komisyonları kurulmuştur.

\section{EĞiTIMDE STANDARDIZASYONUN GEREKLiLIĞi VE YETKi}

Ülkemizde sağlık hizmetinin kalitesi temelde Sağlık Bakanlığı ve Türk Tabipler Birliği'nin sorumluluğu altındadır. Ancak farklı uzmanlık alanlarında yetişen hekimlerin kalitesi, ilgili uzmanlık derneklerini de dolaylı yoldan sorumlu kılmaktadır. Bunun bilincinde ve sorumluluğunda olan TOTBID, TOTEK'i kurarak belli standartlarda ortopedi ve travmatoloji uzmanının yetişmesini ve bu standardın mezuniyet sonrasında sürdürülmesini sağlamayı amaçlamıştır.

Türkiye'de halen yaklaşık 100 kurumda 850 meslektaşımıza ortopedi ve travmatoloji uzmanlık eğitimi verilmektedir. Kurum sayısının çok, eğitici sayısının az oluşu nedeniyle eğitimin standardizasyonu kaçınılmaz bir gerekliliktir. Bu aşamada TOTBID-TOTEK, yetkinlik nedeniyle kurumlar ve kişiler üzerinde doğrudan etkin olamamaktadır. Bir sivil toplum örgütü olarak, ancak üyelerin katılımı ve talep etmesi dolayısıyla -resmi olmayan- fiili bir yetkinlik oluşmaktadır.

\section{EĞiTIMDE TEMEL KAVRAMLAR}

Tıp eğitiminde son yıllarda bir paradigma kayması yaşanmaktadır: Eskiden usta-çırak ilişkisi şeklinde olan eğitim yavaş yavaş yerini yeni tekniklerin kullanıldığı (kadavra, maket kemik uygulamaları, simülasyonlar) modern eğitim yöntemlerine bırakmaktadır. Usta-çırak ilişkisiyle yapılan eğitimde özellikle cerrahi branşlarda hasta güvenliğinin azaldığı ve komplikasyonların arttığı gösterilmiştir. ${ }^{[2]}$ Eğitimin evrensel olarak kabul edilen temel taşları vardır. Bunlar program geliştirme ile ölçme ve değerlendirmedir. Her iki temel kavram için TOTEK'te her dönem yönetim kurulu üyeleri ilgili komisyonlarda görevlendirilmektedir. Program geliştirilirken eğitim alacak olan topluluğa verilmesi gerekenler, bilgi, beceri ve tutum olarak üç grupta toplanır. Ortopedi ve travmatoloji uzmanlığının cerrahi bir branş olması dolayısıyla, becerinin bilgi kadar önemli olduğu ortadadır. ${ }^{[3]}$

Eğitimin diğer ayağı ölçme ve değerlendirmedir. Verilen eğitim programının uzmanlık öğrencisi tarafından ne kadar alındığını ölçmemize yarar ki ölçmedeğerlendirmedeki ölçütler standardizasyon açısından oldukça önemlidir.

\section{TOTEK'IN EĞiTiM ETKINLIKLERi}

TOTEK, genel bir ortopedi uzmanının bilmesi gereken bilgi, beceri ve tutum düzeyindeki program başlıklarını "Çekirdek Eğitim Programı" (ÇEP) olarak oluşturarak tavsiye niteliğinde eğitim kurumlarıyla paylaşmıştır. Ancak eğitim programı yaşayan bir kavramdır ve zamanın gereklerine yönelik değişebilmelidir. TOTEK her yıl board sınavı öncesi eylül ayı içerisinde, ÇEP kursu düzenlemektedir. Bu kurs genel bir gözden geçirme kursudur. Kursa son sene asistanları ve tüm ortopedi ve travmatoloji uzmanları katılabilmektedir.

Ortopedi Bilgi Ağı (OBA), TOTEK tarafından geliştirilen bir başka eğitim enstrümanıdır. Fikir, alanımızdaki sınırlı Türkçe kaynak sorununu aşmak amacıyla oluşturulmuştur. Temel konulardaki seminer konuları 2009 yılından itibaren internete yüklenmeye başlanmıştır. TOTBID internet sitesinin "TOTBID üyeleri için" sekmesinden üyelik şifresi ile girilebilen bu bölümde 100 temel seminer konusuna ait sunumlar yer almaktadır. ${ }^{[4]}$

TOTEK, ortopedi ve travmatoloji uzmanlık branşının alt dallarına (travma, artroplasti, omuz ve dirsek cerrahisi gibi) ait temel kursları da akredite etmektedir. Bu süreçte özellikle kursun ÇEP'e uygunluğu göz önünde bulundurulmaktadır.

ÇEP'in özellikle beceri bölümünün özeti diyebileceğimiz enstrüman, asistan karneleridir. En son 2013 yılında güncellenen asistan karnesinin içinde bir uzmanlık öğrencisinin hangi rotasyonları yapması gerektiği, hangi yılda hangi girişimlerden kaç adet görmesi ya da uygulaması gerektiği belirtilmektedir. Böylece uzmanlık öğrencisinin karnesine bakıldığında o kişinin beceri anlamında hangi konularda, ne kadar yeterli olduğu kabaca anlaşılabilmektedir. Böylece, eğitim kurumu asistan karnesinin etkin kullanımıyla beceri anlamında standart bir ortopedi ve travmatoloji eğitimi verebilmektedir. Ancak, TOTEK 5. Dönem Kitabı'nda uzmanlık öğrencileri arasında yapılan anketin sonucuna göre, eğitim kurumlarında ortalama asistan karnesi kullanma ve geliştirilen ÇEP'ten yararlanma oranı yıllar içinde azalmaktadır. Bu azalma hem Sağlık Bakanlığı'na hem de üniversitelere bağlı eğitim kurumlarında gözlenmektedir. Aynı ankete göre, birçok eğitim kurumunda yapılandırılmış (haftalık olgu tartışması, seminer, dergi kulübü vb.) bir eğitim programı uygulanmamaktadır. ${ }^{[5]} \mathrm{Bu}$ gözlem ülkemizdeki ortopedi ve travmatoloji eğitimi açısından endişe vericidir. Çünkü her kademede verilen eğitim için, eğitim programı, olmazsa olmaz niteliğindedir.

\section{TOTEK'IN ÖLÇME VE DEĞERLENDIRME ETKINLIKLERi}

TOTEK, bu konuda iki tip ölçme ve değerlendirme sınavı uygulamaktadır. Birincisi "uzmanlık eğitimi gelişim sınavı” (UEGS), diğeri de TOTEK sertifikasyon sınavıdır. 
Tablo 1. TOTEK'in uyguladığı eğitim ve ölçmedeğerlendirme etkinlikleri

\begin{tabular}{ll}
\hline Eğitim & Ölçme ve Değerlendirme \\
\hline Çekirdek Eğitim Programı Kursu & TOTEK Board Sınavı \\
Temel Bilimler ve Araştırma Okulu & Uzmanlık Eğitimi Gelişim Sınavı \\
& Resertifikasyon
\end{tabular}

UEGS, uzmanlık öğrencilerine yönelik olarak yılda bir kez mayıs ayında yapılmakta olup, amacı uzmanlık eğitimi öğrencilerinin aldıkları eğitim ile gelişimlerinin değerlendirilmesidir. Tüm Türkiye'de eğitim kurumlarının tamamında aynı anda uygulanır. Sınav gözlemcileri aynı ildeki ya da komşu illerdeki kurumlardan atanır. Bu bir öz değerlendirme sınavıdır; sonuçlar sadece eğitim kurumunun sorumlusu ve uzmanlık öğrencisiyle paylaşılır. Sınav, sonuçları konu başlıklarına göre ayrılarak verildiği için konu başlıklarına göre eksiklerin algılanmasını sağlar. Sonuçları her yıl alan eğitim kurumu sorumlusu, verdiği eğitim programını geliştirme, eksiklerini tamamlama olanağı bulur. Bunun yanında uzmanlık öğrencisinin kişisel temelde gelişimini de değerlendirebilir. Mayıs 2014'te uygulanan son sınava yaklaşık 850 uzmanlık öğrencisinin 720'si katılmıştır. Katılımın yoğun olması sınavın kalitesini arttırmaktadır.

EBOT (European Board of Orthopaedics and Traumatology) interim deneme sınavı, UEGS sınaviyla aynı amacı taşıyan ve EBOT'un tüm Avrupa'da aynı anda online düzenlediği bir sınavdır. Ülkemizde de kurumların gönüllülük esasına göre katıldığı bu sınav İngilizce düzenlenmektedir. Bu sınavın Avrupa ile aynı anda Türkçe düzenlenerek UEGS sınavının yerini alabileceği konusu, TOTEK yönetim kurulunda halen tartışılan bir konudur.

TOTEK sertifikasyon sınavı yılda bir kez iki aşama halinde son baharda düzenlenir. Sınava son sene asistanlarıly tüm ortopedi ve travmatoloji uzmanları katılabilir. İlk aşama çoktan seçmelidir, teorik bilgiyi ölçmeye dayanır ve baraj sınavıdır. Bu sınavda barajı geçenler ikinci aşamaya girmeye hak kazanır. İkinci aşama sınavı daha çok beceri ve tutumu ölçmeye dayanan istasyonlardan oluşmaktadır. Bu aşamadan da başarıyla geçen aday sertifika kazanmaya hak kazanır.

TOTEK, kuruluşunun 10. yılında resertifikasyon sürecini başlatmıştır çünkü 2001 yılında verilen ilk sertifikaların süresi dolmuştur. Resertifikasyon süreci yöntem olarak TOTEK ve TOTBID yönetim kurullarında tartışılmıştır. Yöntem olarak portfolyo yöntemi benimsenmiştir. Bunun için resertifikasyon için başvuran uzman son 10 yıl içinde gerçekleştirdiği eğitim ve bilimsel etkinliklerini bir portfolyoda toplayarak başvurusunu yapar.

\section{EĞiTIM KURULTAYLARI}

TOTEK-TOTBID işbirliği ile üç adet eğitim kurultayı düzenlenmiştir. Her kurultay sonunda bir sonuç bildirgesi yayımlanarak ortopedi ve travmatoloji alanında eğitim stratejisi belirlenmeye çalışılmıştır.

Kurultaylardan sonuncusu 1-2 Nisan 2011 tarihinde Marmara Üniversitesi'nde düzenlenmiştir. Değişik kurumlardan temsilcilerin (uzmanlık öğrencisi temsilcisi, Sağlık Bakanlığı temsilcisi, TOTBiD temsilcisi, TOTEK temsilcisi, Sağlık Bakanlığı eğitim hastanesi temsilcisi, üniversite hastanesi temsilcisi, EBOT temsilcisi) katıldığı toplantıda ortopedi ve travmatoloji eğitimiyle ilgili sorunlar tanımlanmıştır. Tanımlanan belli başı ı sorunlar şunlardır: ÇEP oluşturulmalı; eğitim kurumları bu ÇEP'e uymalı; hekime uygulanan şiddet eğitimi olumsuz etkilemektedir; yetersiz asistan sayısı eğitimi olumsuz etkilemektedir; performans sistemi eğitimi olumsuz etkilemektedir; eğitici sayısı arttırılmalıdır. ${ }^{[6]}$

\section{ÇIKARIMLAR}

Ülkemiz gibi sağıı ve eğitim politikalarının değişken olduğu ülkelerde ortopedi ve travmatoloji eğitiminde strateji belirlenmesi oldukça önemlidir. Bu stratejilerin başında eğitimin standardize edilmesi ve kurumlara göre değişken olmasının engellenmesi gelmektedir. Bu saptama çerçevesinde, TOTBID'in eğitimden sorumlu organı TOTEK'e önemli görevler düşmektedir. Ancak, bu görevlerin etkin biçimde icra edilebilmesi için meslektaşlarımızın katılımcı olması ve derneklerini desteklemeleri önemlidir. Böylece yetki karmaşası aşılmış olacak ve ortopedi ve travmatoloji eğitiminin düzeyi, kişi ve kurumlardan bağımsız olarak, standart biçimde kaçınılmaz olarak artacaktır.

\section{KAYNAKLAR}

1. http://totek.totbid.org.tr/Content.aspx?p=1631

2. Pedowitz RA, Marsh JL. Motor skills training in orthopaedic surgery: a paradigm shift toward a simulation-based educational curriculum. J Am Acad Orthop Surg 2012;20(7):407-9. doi: 10.5435/JAAOS-20-07-407

3. Pitts D, Rowley DI, Marx C, Sher L, Banks T, Murray A (BOTA). A competency based curriculum 2007. Specialist Training in Trauma and Orthopaedics. Lincoln's Inn Fields, London: British Orthopaedic Association; 2006.

4. Arazi M. Ortopedi Bilgi Ağı (OBA). TOTBID-TOTEK 5. Dönem Kitabı. Ankara: Başak Matbaacılık; 2011. s.52-4.

5. Kesmezacar H. Asistan Anketi Çalışma Raporu. TOTBiDTOTEK 5. Dönem Kitabı. Ankara: Başak Matbaacılık; 2011. s.109-24.

6. http://www.totbid.org.tr/upload/III.\%20EĞiTiM\%20 ÇALIŞTAYI\%20KITABI.pdf 